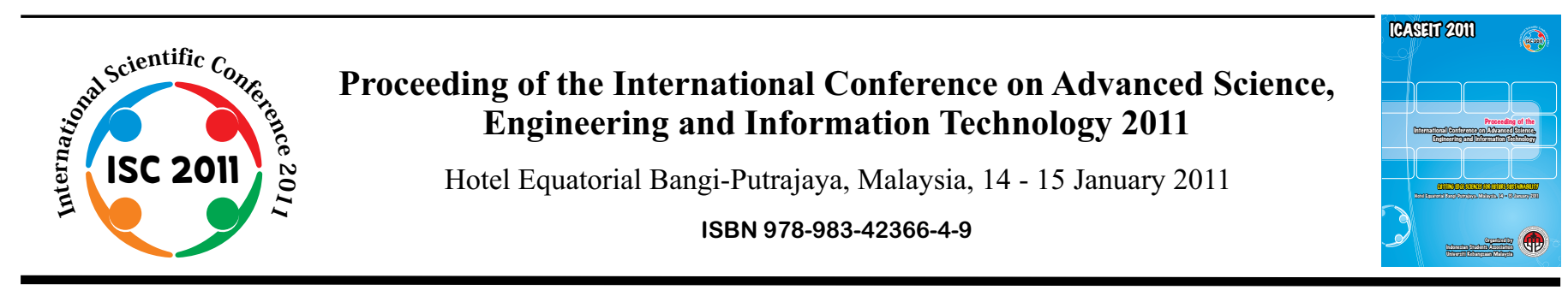

\title{
Investigation of Power Factor on Harmonic Effect due to Types of Voltage Source
}

\author{
${ }^{1}$ Risnidar C.B, ${ }^{1}$ Ismail Daut, ${ }^{1}$ M.I. Yussof, ${ }^{2}$ Eddy Warman, ${ }^{2}$ Masykur, ${ }^{1}$ S. Hasan, ${ }^{1}$ I. Nisja \\ ${ }^{I}$ Electrical Engineering Department, University Malaysia Perlis (UniMAP), Kangar, \\ Perlis, 01000, Malaysia \\ Tel.:+60164098982,E-mail: risnidar@unimap.edu.my \\ ${ }^{2}$ Electrical Engineering Department, Universitas Sumatera Utara, Medan, Indonesia \\ F.T. USU, Kampus USU, Medan, Indonesia \\ Tel.:+628126502649,E-mail: edywarman@yahoo.com
}

\begin{abstract}
This paper discussed about power factor on harmonic effect due to types of voltage source. Usually, the voltage source is sinusoidal. But in actual condition the load that has voltage sources through the elements where the output voltage of element as input to load is not pure sinusoidal, for example at Power of Common Coupling (PCC) between transformer and linear load and nonlinear load. The research has been done with Schhafner Power Quality Analyzer and was focused to power factor (p.f.), Total Harmonic Distortion (THD), and harmonic energy losses cost from measurement where load is Induction motor and Adjustable Speed Drive (ASD). As voltage source in this research are sine wave, square wave and combinations of $3^{\text {rd }}, 5^{\text {th }}$ and $7^{\text {th }}$ harmonic order like harmonic 313, and harmonic 357.
\end{abstract}

Keywords - type of voltage source, power factor, energy losses cost, harmonic

\section{INTRODUCTION}

This research is discussing the kinds of voltage sources used to serve the load, such as sine wave, square wave and the combination of the harmonics order, so it is necessary to discuss about Fourier series. Because to analyze the harmonics, applied the Fourier series is appropriate. Actually, Fourier series is a periodic function can be written as sums of infinitely many sine and cosine functions of different frequencies [1] R.J. Beerends et al (2003), often expressed in terms of the angular frequency. Harmonic waveform distortion is one of the most important issues today. In this paper discuss about investigation of harmonic effect due to harmonic types of voltage source, where voltage sources are a few types of harmonic waveform. This case is as a part of system, where if a Point of Common Coupling (PCC) of one component nonlinear load has supplied with another nonlinear load. In this research, the load is Induction Motor with Adjustable Speed Drive (ASD) was supplied with Sine waveform, Square wave and Harmonic $3^{\text {rd }}, 5^{\text {th }}$, and $7^{\text {th }}$ combination waveform. The meaning of voltage source as harmonic $3^{\text {rd }}, 5^{\text {th }}$ and $7^{\text {th }}$ combinations is voltage that was created by Schhafner Power Quality Analyser. The presence of harmonic distortion in the applied voltage to a motor will both increase electrical losses and decrease efficiency. These losses will increase motor temperature, resulting in even further losses These currents passing through the system impedance cause voltage drops for each individual harmonic, resulting in distortion of the voltage's waveform. The effect of harmonic distortion of the voltage waveform due to impacts motor performance as p.f. IHD and THD for current and voltage, and energy losses due to harmonic. [2][3][4].

One of main harmonics characteristic is: p.f. This is a measure of how effectively a specific load consumes electricity to produce work. The higher of power factor, the more work produced for a given voltage and current. The relationships between power vector to explain about power factor as Figure 1. From Figure 1, the relationship between power and power factor for Linear Loads and Non-Linear Loads are as follow: 
a. Linear Loads

$$
\begin{aligned}
& \text { p.f. }=\frac{P}{S}=\frac{k W}{k V A}=\cos \varphi \\
& S=\sqrt{P^{2}+Q^{2}} \\
& k V A=\sqrt{k W^{2}+k V A R^{2}}
\end{aligned}
$$

b. Non-Linear Loads

$$
\begin{aligned}
& p . f .=\frac{P}{S}=\frac{k W}{k V A}=\cos \varphi \\
& S=\sqrt{P^{2}+Q^{2}} \\
& k V A=\sqrt{k W^{2}+k V A R^{2}+k V A R_{H}^{2}}
\end{aligned}
$$

Power Factor total $=($ Displacement p.f) $x$ (Distortion p.f.), where Displacement power factor is the ratio between load power and apparent power of fundamental component, while Distortion Power Factor or true power factor emerges as the index that tracks rms signal variations.

The others characteristic of harmonic are:

The values of $V_{\text {rms }} I_{r m s}$, Power $(P)$, were calculated directly from the harmonic components obtained with a Fast Fourier Transform of the sampled data of the voltage and current waveforms of the Induction Motor under tests. These quantities were calculated as:[3][4][5][6]

$$
\begin{aligned}
& V_{r m s}=\sqrt{\sum_{h=1}^{\infty} V_{h}^{2}} \text { and } I_{r m s}=\sqrt{\sum_{h=1}^{\infty} I_{h}^{2}} \\
& P=\sum_{h=1}^{\infty} V_{h} I_{h} \cos \varphi_{h} \text { and } S=V_{r m s} I_{r m s}
\end{aligned}
$$

where $V_{h}, I_{h} \varphi_{h}$ are magnitudes and phase shift of the voltage and current, $h$ order harmonic.

The factor that measures the distortion in the non sinusoidal wave is Total Harmonic Distortion (THD) where this factor is defined for both voltage and current as below:

$$
T_{I}=\frac{\sqrt{\sum_{h=2}^{\infty} I_{h}^{2}}}{I_{1}} \text { and }{ }_{T H D_{V}}=\frac{\sqrt{\sum_{h=2}^{\infty} V_{h}^{2}}}{V_{1}}
$$

\section{Methodology}

From the measurement of induction motor with Shaffner, where the voltage source to load is varieties are: sinusoidal, and a few harmonics waveforms. And the load is three phase induction motor. These experiments are done, because to investigated the effect of voltage source type of harmonic to served load. Because at any PCC in power system, the load maybe find source did not pure sinusoidal, for example from secondary of transformer. The main characteristic of harmonics are Individual Harmonic Distortion (IHD) for $3^{\text {rd }}, 5^{\text {th }}$ and $7^{\text {th }}$, Total Harmonic Distortion (THD) for voltage and current, Power losses due to harmonics, power factor, Cress factor for each harmonics, $I_{\text {rms }}, V_{\text {rms. }}$. The measurements are done with voltage sources variable from $160 \mathrm{~V}$ until $240 \mathrm{~V}$. For voltage source type Harmonic 313 its mean voltage source as combination from $3^{\text {rd }}$ harmonic order and fundamental, while voltage source harmonic 357 it mean is voltage source as combination from $3^{\text {rd }}, 5^{\text {th }}$ and $7^{\text {th }}$ harmonic orders. All of the voltage sources are create from the Schhafner Power Quality Analyzer

With linear loads
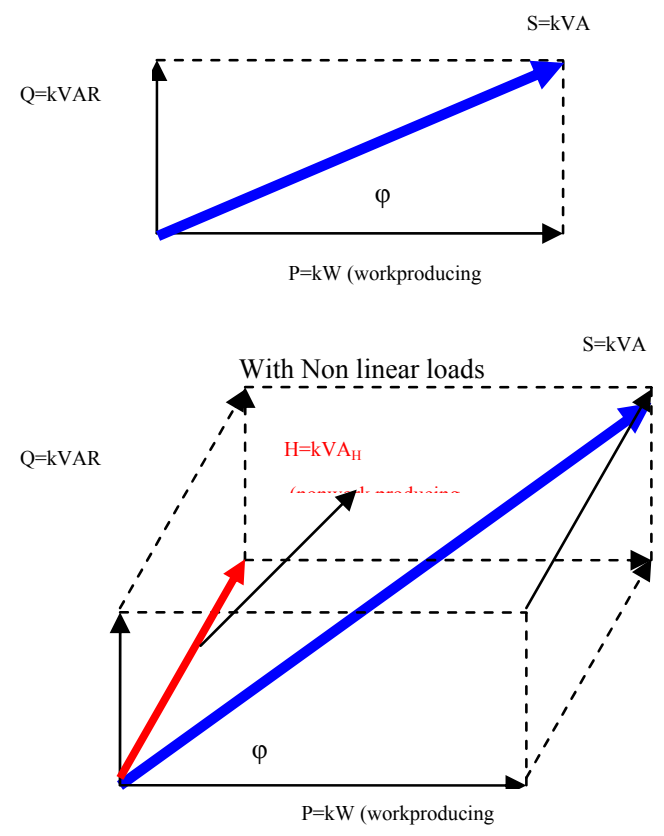

Figure1. Power factor relationship for Linear and NonLinear loads

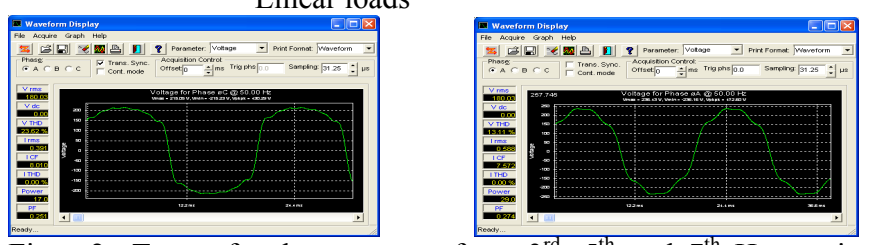

Figure2. Type of voltage source from $3^{\text {rd }}, 5^{\text {th }}$ and $7^{\text {th }}$ Harmonic order combinations

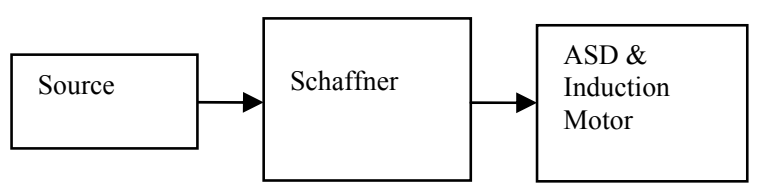

Figure3. Induction Motor Measurement

The type of voltage source from combination of harmonic order $3^{\text {rd }}, 5^{\text {th }}$ and $7^{\text {th }}$ are as Figure 2:

The Induction motor specifications are: 3 phase, $1.5 \mathrm{Hp}$, $50 \mathrm{~Hz}, 1370 \mathrm{rpm}, 4$ poles. The measurements have done with ASD.

\section{DATA AND RESULT}

Data and result base direct measurements to Induction motor 3 phase, $1.5 \mathrm{Hp}, 50 \mathrm{~Hz}, 1370 \mathrm{rpm}, 4$ poles are as follow:

Table1. Type of voltage source Vs, power active, Apparent Power, p.f

\begin{tabular}{|l|l|l|l|l|}
\hline $\mathrm{V}_{\text {source }} \mathrm{A}$ & $\mathrm{P}(\mathrm{kW})$ & $\mathrm{S}(\mathrm{kVA})$ & p.f. & C.F. \\
\hline Harm 313 & 0.0348 & 0.1754 & 0.306 & 1.894 \\
\hline Harm 357 & 0.0354 & 0.1802 & 0.304 & 1.73 \\
\hline Sine & 0.0362 & 0.1816 & 0.316 & 1.528 \\
\hline Square & 0.0366 & 0.1696 & 0.32 & 2.292 \\
\hline
\end{tabular}


Table2. Type of voltage source Vs IHD and THD voltage

\begin{tabular}{|l|l|l|l|l|}
\hline \multicolumn{1}{|c|}{$\mathrm{V}_{\text {source }} \mathrm{A}$} & \multicolumn{1}{c|}{$3^{\text {rd }} \mathrm{V}$} & \multicolumn{1}{c|}{$5^{\text {th }} \mathrm{V}$} & $7^{\text {th }} \mathrm{V}$ & \multicolumn{1}{c|}{ THDV } \\
\hline Harm 313 & 20.114 & 10.038 & 6.986 & 23.618 \\
\hline Harm 357 & 10.036 & 7.02 & 4.958 & 13.096 \\
\hline Sine & 0.126 & 0.024 & 0.008 & 0.21 \\
\hline Square & 33.432 & 19.912 & 13.964 & 41.192 \\
\hline
\end{tabular}

Table3. Type of voltage source Vs IHD and THD current

\begin{tabular}{|l|l|l|l|l|}
\hline \multicolumn{1}{|c|}{$\mathrm{V}_{\text {source }} \mathrm{A}$} & \multicolumn{1}{c|}{$3^{\text {rd }} \mathrm{I}$} & \multicolumn{1}{c|}{$5^{\text {th }} \mathrm{I}$} & \multicolumn{1}{c|}{$7^{\text {th }} \mathrm{I}$} & \multicolumn{1}{c|}{ THDi } \\
\hline Harm 313 & 1.804 & 22.494 & 10.792 & 24.6 \\
\hline Harm 357 & 0.842 & 15.836 & 7.676 & 17.372 \\
\hline Sine & 0.17 & 0.616 & 0.378 & 1.178 \\
\hline Square & 2.9 & 43.726 & 22.084 & 44.92 \\
\hline
\end{tabular}

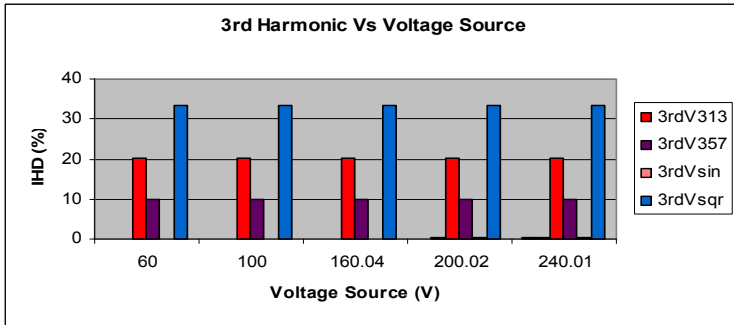

Figure4. Voltage Source Vs $5^{\text {th }}$ Harmonic Voltage

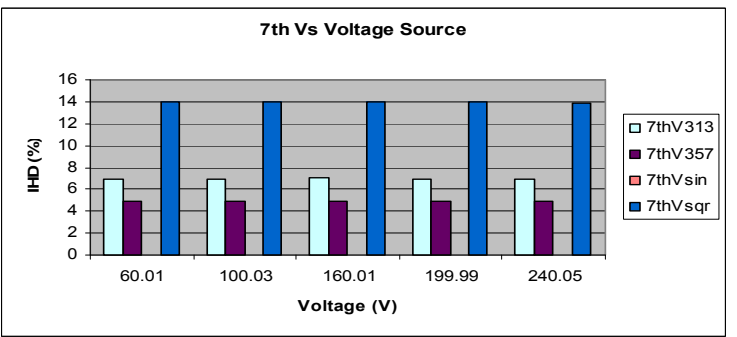

Figure5. Voltage Source Vs $7^{\text {th }}$ Harmonic Voltage

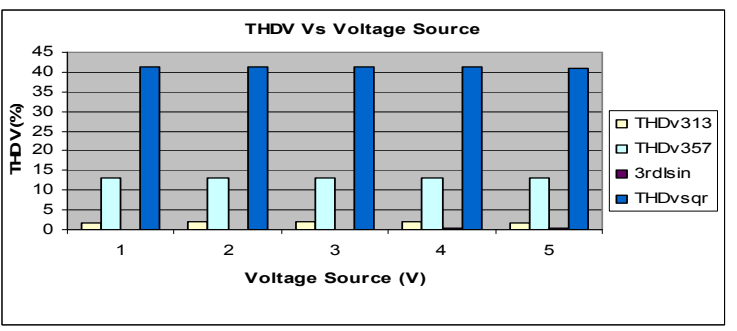

Figure6. Voltage Source Vs THD Voltage

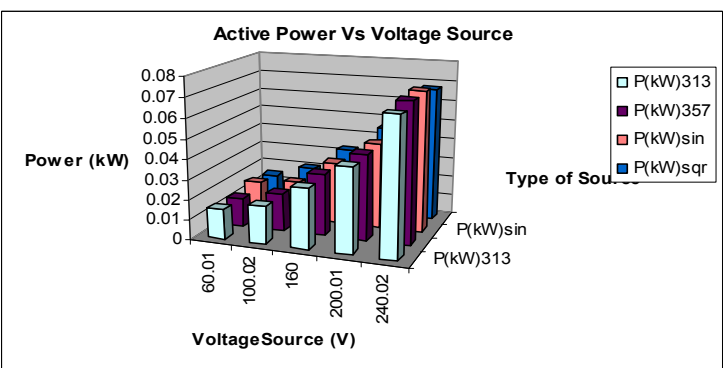

Figure7. Voltage Source Vs Active Power
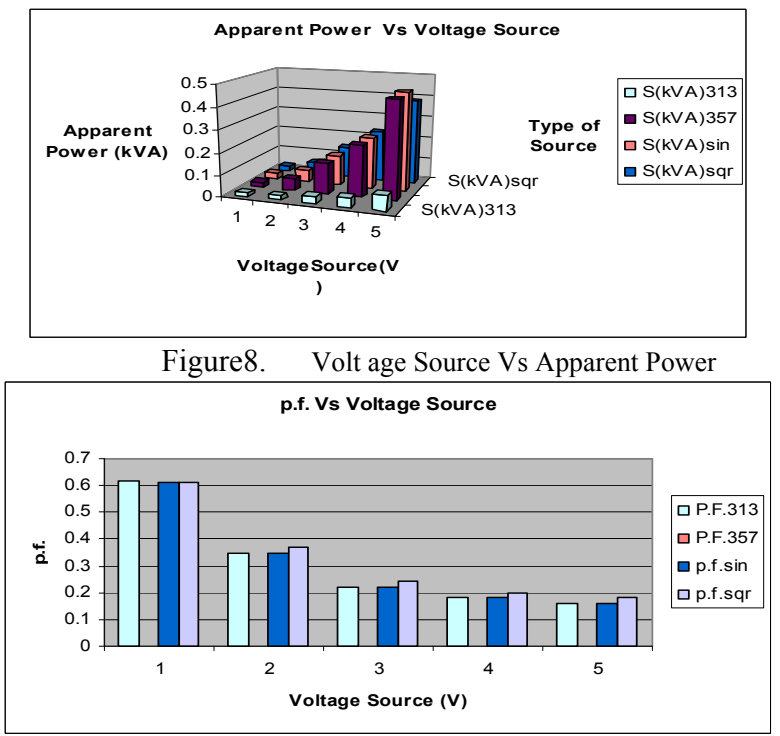

Figure9. Voltage Source Vs power factor

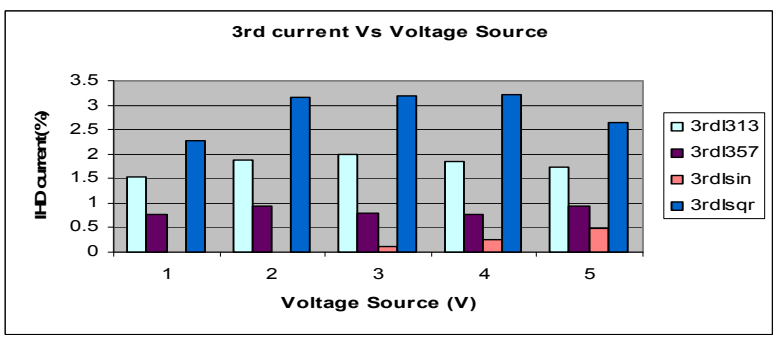

Figure10. Voltage Source Vs $3^{\text {rd }}$ Harmonic Current

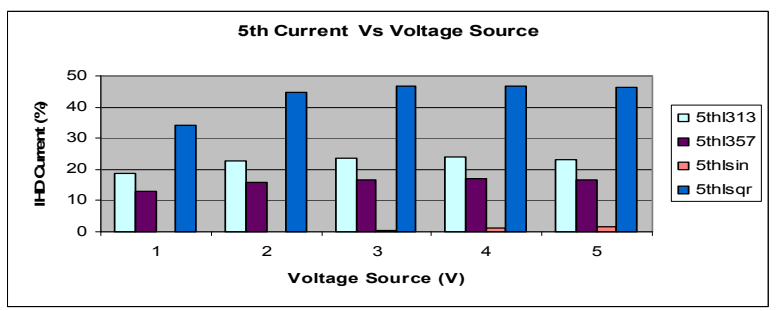

Figure11. Voltage Source Vs $5^{\text {th }}$ Harmonic Current

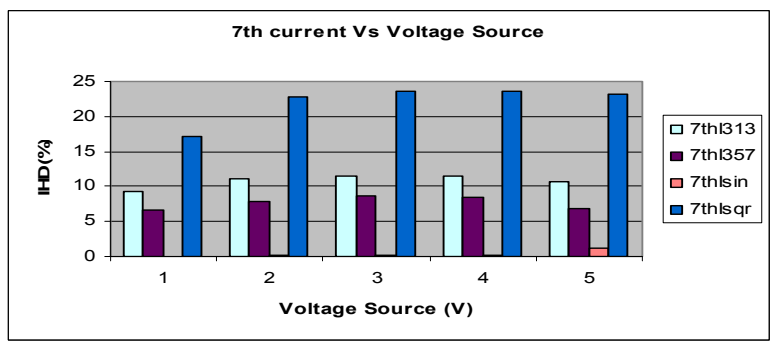

Figure12. Voltage Source Vs $7^{\text {th }}$ Harmonic Current

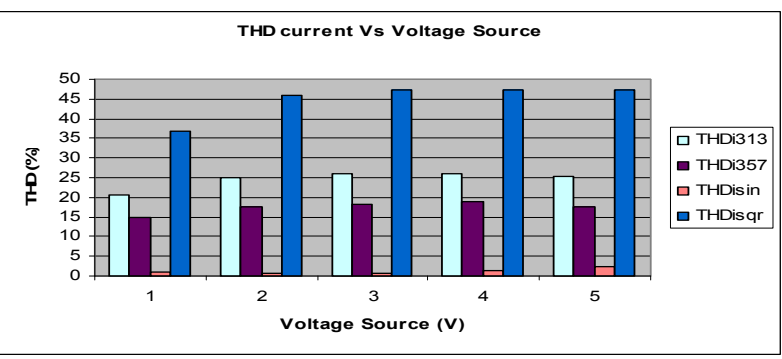

Figure13. Voltage Source Vs THD Harmonic Current 


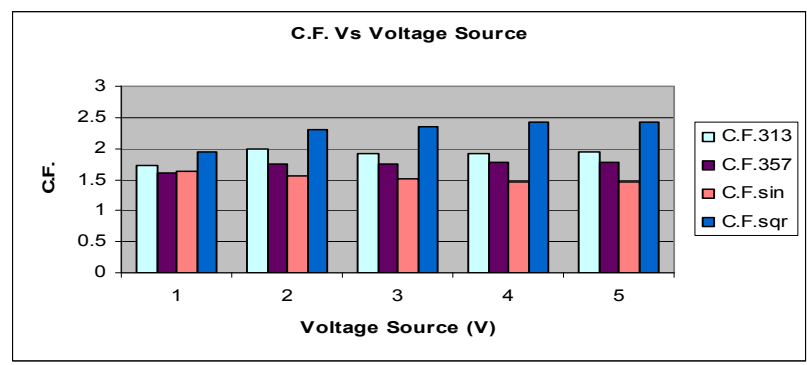

Figure14. Voltage Source Vs Crest Factor

In this experiment, the analysis is focused of influence the voltage source type on harmonic characteristic as:

\section{1. $3^{\text {rd }}$ harmonic voltage}

The $3^{\text {rd }}$ harmonic with voltage square waveform is the largest voltage (about $33.432 \%$ ), because for this waveform the distortion is high where the smallest distortion is sinusoidal waveform (about $0.126 \%$ ), because this waveform is a fundamental waveform. Hence, for harmonic waveform source, the harmonic 313 is large (about 20.114\%) harmonic 357 (about $10.036 \%$ ) is small. All of these due to harmonic $5^{\text {th }}$ are dominant.

\section{2. $5^{\text {th }}$ harmonic voltage}

The $5^{\text {th }}$ harmonic with voltage square waveform is the largest voltage $(19.912 \%)$, because for this waveform the distortion is high. And the small distortion is sinusoidal waveform $(0.024 \%)$, because this waveform is a fundamental waveform. For harmonic waveform source, the harmonic $313(10.038 \%)$ is larger than harmonic $357(7.02 \%)$ due to harmonic $3^{\text {rd }}$ that dominant.

\section{3. $7^{\text {th }}$ harmonic voltage}

The $7^{\text {th }}$ harmonic with voltage square waveform is the largest voltage (13.964\%), because the distortion of this waveform is high. And the small distortion is sinusoidal waveform $(0.008 \%)$, because this waveform is a fundamental waveform. For harmonic waveform source, the harmonic $357(4.958 \%)$ is smaller than harmonic 313 $(6.986 \%)$. These are due to the dominant distortion of harmonic $7^{\text {th }}$.

\section{THD harmonics voltage}

The voltage square vs THD voltage harmonic experiment showed that the $\mathrm{THD}_{\mathrm{V}}$ with voltage square waveform has the largest distortion (about 41.192\%), because for this waveform the distortion is high, and the smallest distortion is sinusoidal waveform $(0.21 \%)$.

\section{5. $3^{\text {rd }}$ harmonic current}

The $3^{\text {rd }}$ harmonic current with voltage square waveform is largest $(2.90 \%)$, because for this waveform the distortion is high. And the small distortion for harmonic waveform source is harmonic $357(0.842 \%)$, and sinusoidal $(0.17 \%)$ is smaller than $313(1.804 \%)$

\section{6. $5^{\text {th }}$ harmonic current}

The $5^{\text {th }}$ harmonic current with voltage square waveform is largest $(43.726 \%)$, because for this waveform the distortion is high. And the small distortion for harmonic waveform source is harmonic $357(15.836 \%)$ than harmonic 313 $(22.494 \%)$ And sinusoidal $(0.616 \%)$ is smallest as fundamental.

\section{7. $7^{\text {th }}$ harmonic current}

The $7^{\text {th }}$ harmonic current with voltage square waveform is largest $(22.084 \%)$, because for this waveform the distortion is high. And the small distortion for harmonic waveform source is harmonic $357(0.378 \%)$ than harmonic 313 $(10.792 \%)$. And sinusoidal $(0.378 \%)$ is smallest as fundamental.

\section{THD harmonic current}

$\mathrm{THD}_{\mathrm{i}}$ with the sinusoidal waveform is small distortion $(1.178 \%)$, because for this waveform it is as fundamental waveform. The voltage square waveform is largest (44.92\%), because for this waveform the distortion is high. For harmonic waveform source, the harmonic 313 is largest $(24.6 \%)$ and then the harmonic $357(17.372 \%)$.

\section{Current peak}

The $\mathrm{I}_{\text {peak }}$ with voltage square waveform is largest (2.2226A), because for this waveform the distortion is high. And the small distortion is sinusoidal waveform (1.495A), because for this waveform it is as fundamental waveform. For harmonic waveform source, the harmonic 313 is largest $(1.8464 \mathrm{~A})$ and then the harmonic 57 (1.827A), and harmonic 357 (1.722A).

\section{0. power factor (p.f.)}

The power factor (p.f) with voltage square waveform is largest (0.32), because for this waveform the distortion is high. And then is sinusoidal waveform (0.316). For harmonic waveform source, the harmonic 313 is largest (0.306) and then the harmonic 357 (0.304).

\section{Active power}

The active power with voltage square waveform is largest $(0.0388 \mathrm{~kW})$, because for this waveform the distortion is high. And then is sinusoidal waveform $(0.0362 \mathrm{~kW})$. For harmonic waveform source, the harmonic $357(0.0354 \mathrm{~kW})$ is bigger than harmonic $313(0.0348 \mathrm{~kW})$.

\section{Apparent power}

The apparent power with voltage square waveform is smallest $(0.1696 \mathrm{kVA})$, because for this waveform the distortion is high. And the sinusoidal waveform is $(0.1816 \mathrm{kVA})$. For harmonic waveform source, the harmonic $357(0.1802 \mathrm{kVA})$ and then the harmonic $313(0.1754 \mathrm{kVA})$ is the smallest.

\section{Cress Factor (C.F.)}

Cress Factor (C.F) is the ratio between The C.F. with sine wave, is constant (1.528), while for harmonic 313 (1.894) is higher then harmonic 357 and square wave is highest (2.292). The harmonics and square wave are increase proportional with voltage source. 


\section{CONCLUSION}

From the results can be drawn the conclusions as follows:

1. Sinusoidal waveform is better than square waveform to harmonic effect; because the square waveform was have distortion from sinusoidal waveform.

2. Crest Factor for sine wave is constant for variety voltage, while for square wave is proportional with voltage value

3. Distortion due to square wave is larger than sine wave

4. Voltage source due to combination of harmonic 357 is better than harmonic 313 because almost all the harmonic characteristics such as p.f., THD, IHD, active power, apparent power is better than the harmonic 313 .

5. Voltage source due to combination of harmonics is better than square wave

6. Real power due to various voltages is highest for square wave, but for apparent power is smallest.

\section{ACKNOWLEDGMENT}

The authors would like to express their gratitude to the Fundamental Research Grant Scheme (FRGS), School of Electrical System Engineering of Universiti Malaysia Perlis (UniMAP) and Power Electronics and Electrical Machine Design Research Cluster for the supply of research facility respectively.

\section{REFERENCES}

[1]. R. J. Beerends, H. G. ter Morshe, J. C. van den Berg and E. M. van de Vrie, "Fourier and Laplace Transforms", Translated from Dutch by R.. J. Beerends, Cambridge University Press, 2003.

[2]. Peter Bechard, "Fault ZoneAnalysis POWER QUALITY”, The 2004 Motor Reliability Technical Conference, PdMA Corporation.

[3]. Barry W. Kennedy, POWER QUALITY PRIMER, McGraw-Hill, Singapore, 2000

[4]. Francisco C. De La Rosa, "Harmonics and Power Systems", Taylor \& Frencis, CRC, Boca Raton, 2006.

[5]. J. Arrilaga, B.C.Smith, N.R. Watson, A.R. Wood, POWER SYSTEM HARMONIC ANALYSIS, John Wiley \& Sons, Singapore, 2000

[6]. IEEE Recommended Practices and Requirements for Harmonic Control in Electrical Power Systems 